\title{
EL DISCURSO DE OBAMA SOBRE LA POLÍTICA ECONÓMICA DE LOS ESTADOS UNIDOS Y EL IMPACTO PROBABLE EN PERÚ
}

Gilberto Cárdenas Núñez (")

E-mail: rafaelcardenasn@hotmail.com

\section{RESUMEN}

Perú trata de enfrentar la crisis financiera, económica y progresivamente política con un plan contra ella. En el presente artículo analizaremos las perspectivas y realidades del entorno y de la situación nacional.

Palabras clave: Crisis Política, Crisis Económica, Perspectivas, Barack Obama.

\section{ABSTRACT}

Peru tries to face the financial, economic and progressively political crisis with a plan against the crisis. In this article we will analyze the perspectives and realities of the environment and our national situation

Key words: Political crisis, Economic Crisis, Perspectivas, Barack Obama.

(*) Magíster en Planificación del Desarrollo y candidato a Doctor en Ciencias Contables y Empresariales. Economista. Director del Instituto de Investigaciones Económicas de la Facultad de Ciencias Económicas de la Universidad Nacional Mayor de San Marcos. 


\section{INTRODUCCIÓN}

Me llamó poderosamente la atención un mensaje sobre la vida del actual presidente de los Estados Unidos de América, en el cual se aprecia a su madre Ann Dunham, antropóloga y luchadora por los derechos ciudadanos, hija de padres de clase media norteamericana (él, empleado de una empresa y ella ama de casa), graduada en la Universidad de Hawai, casada en primeras nupcias con el keniano Obama, y en segundas nupcias con un indonesio.

Barack Obama fue criado casi exclusivamente por sus abuelos desde los diez años de edad, en una familia diferente (abuelo, abuela, madre, medio hermana de padre indonesio y él) ${ }^{1}$. Ese es el origen cultural y el ambiente familiar que influyeron en él desde sus primeros años de vida.

Hoy, en medio de una crisis financiera, económica y progresivamente social que tiene como centro los propios Estados Unidos de América, Obama envía un mensaje al mundo en el cual se destacan algunas líneas de política económica mundial que impactarán notablemente en la frágil economía peruana.

Analizar el mensaje y los probables impactos que tendrá en la economía peruana es urgente e importante, pues el destino de muchos connacionales se verá afectado por las decisiones que deriven de la situación de crisis, que pueden ser aminoradas o agravadas por las decisiones anti crisis del segundo gobierno de Alan García.

\section{EL DISCURSO DE OBAMA}

Recibí por Internet la traducción del discurso de Barack Obama, en una versión que me parece aceptable $^{2}$. En base a ella analizaré las repercusiones que tendrán sus intenciones y objetivos de política económica en países como Perú, que pugnan por salir de la situación de atraso y subdesarrollo desde hace décadas y que, contando con condiciones favorables, aún no puede encontrar la senda del crecimiento sostenido y del desarrollo económico.

Casi al inicio su discurso recae en la crisis como entorno condicionante de su gobierno.
Así dice:

"Que estamos en medio de una crisis es algo muy asumido. Nuestra nación está en guerra frente a una red de gran alcance de violencia y odio. Nuestra economía está gravemente debilitada, como consecuencia de la codicia y la irresponsabilidad de algunos, pero también por el fracaso colectivo a la hora de elegir opciones difíciles y de preparar a la nación para una nueva era"3.

Interesante la apreciación sobre la actitud de los banqueros de inversión norteamericanos y del mundo occidental en general, pues considera que su actuar es codicioso e irresponsable, pero también señala el error social de haber elegido gobernantes que llevaron al fracaso a la economía americana.

La banca de inversión está dedicada a la intermediación de activos financieros, la renta fija, la Bolsa y productos sofisticados, y es propia de los mercados muy desarrollados.

"Tiene tres grandes ventajas frente a la 'aburrida' (como la definen muchos) banca de oficinas y pequeños clientes. Por un lado, necesita menos empleados. Por ejemplo, Lehman tenía 25,900 empleados mientras que el Santander, por ejemplo, tiene 132,000 trabajadores. A la vez, se obtienen más beneficios en menos tiempo, lo que lo convierte en un negocio rentable y goloso, sobre todo cuando sopla el viento a favor. Además, la banca de inversión es relativamente fácil de exportar de un país a otro, ya que se puede aprovechar todo el potencial que se posee en los cuarteles generales del país de origen. Por ejemplo, la filial española de Lehman era muy rentable con sólo 45 empleados". ${ }^{4}$

En el Perú no hay banca de inversión, pero eso no es de conocimiento generalizado debido a que para los empresarios y consumidores la banca es la banca, sin hacer mayores distinciones. Como señala el diario El País, una ventaja es que se pueden obtener beneficios elevados y en el corto plazo, sobre todo si se trabaja con dinero ajeno y se cobra una comisión por las operaciones o

1 El archivo de power point titulado Obama llegó a través de la Red Mundial de Científicos Peruanos pocos días antes que el presidente de Estados Unidos asumiera el cargo.

2 Proviene de la dirección vladi98mb@yahoo.es.

3 Obama, Barack. Discurso del 21 de enero del 2009 en la Casa Blanca, Washington, Estados Unidos de América.

4 Diario El País. “La banca de Inversión, un Negocio Arriesgado”. Madrid, 16 de septiembre del 2008. 
por los beneficios. Esto es concebido por Obama como codicia.

Continúa seguidamente con una apreciación espectacular:

"Se han perdido casas y empleos y se han cerrado empresas. Nuestro sistema de salud es caro; nuestras escuelas han fallado a demasiados; y cada día aporta nuevas pruebas de que la manera en que utilizamos la energía refuerza a nuestros adversarios y amenaza a nuestro planeta"5.

La manifestación de las fallas del funcionamiento de la economía norteamericana, para Obama, estriba en la vivienda, el empleo, la salud, la educación y la energía. El origen está en la codicia y en el error colectivo al elegir gobernantes. Es importante indicar que tales conceptos están completamente alejados de los planteamientos neoclásicos, en los cuales la búsqueda de ganancias o utilidad es el móvil de las empresas y de los consumidores. Por allí que se vislumbra un notable cambio en la conducción de la política económica y su influencia en los gobernantes y políticas económicas de Perú y América Latina.

Las cifras de la perspectiva económica para el 2009 le dan la razón cuando señala que cada día las pruebas de la crisis continúan. Así, en el siguiente gráfico podemos apreciar lo que optimistamente se ve que viene este año ${ }^{6}$ (ver Gráfico №1):

\section{Gráfico N $^{0}$}

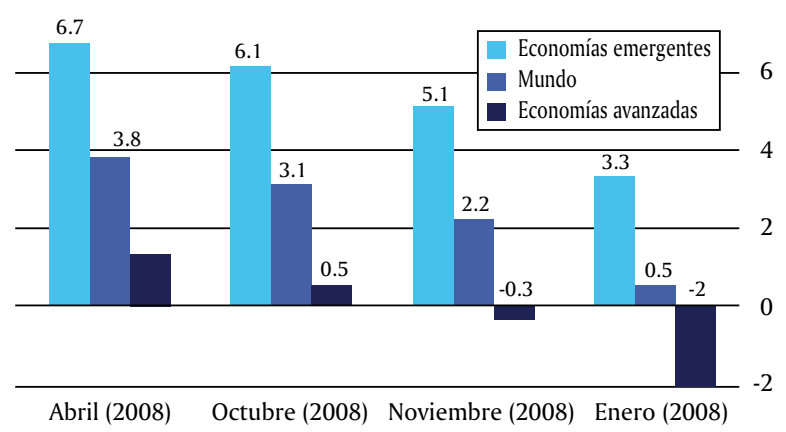

Los analistas temen cada nueva cifra o hecho que sale sobre el comportamiento de la economía de los Estados Unidos de América o de la Unión Europea, porque obliga a recalcular las estimaciones, casi siempre hacia la baja. Tal es el caso de la caída del gobierno democrático de Islandia debido a la insostenible situación económica de su país. Hechos de este tipo indican que la crisis sigue transfiriendo consecuencias, como en esta situación en que llega al ámbito político. Imagino que no es el último caso, sólo que es muy difícil imaginar cuál es el siguiente gobierno democrático que colapsará.

Obama considera su propio país como una nación especial. Es claro esto porque los Estados Unidos de América generan el 25\% del Producto Bruto Interno del mundo. Así:

"Seguimos siendo la nación más próspera y
poderosa de la tierra. Nuestros trabajadores
no son menos productivos que cuando empezó
esta crisis. Nuestras mentes no son menos
inventivas, nuestros bienes y servicios no son
menos necesarios que la semana pasada, el
mes pasado o el año pasado. Nuestra capa-
cidad no ha disminuido. Pero el tiempo del
inmovilismo, de la protección de intereses
limitados y de aplazar las decisiones desagra-
dables, ese tiempo seguramente ha pasado. A
partir de hoy debemos levantarnos, sacudirnos
el polvo y volver a empezar la tarea de rehacer
Estados Unidos"?

¿Significa esto el fin del sistema económico prevaleciente en los Estados Unidos de América? Al parecer no, pero el mandatario señala que es el fin del no hacer nada y continuar protegiendo intereses creados al amparo de la gran nación. Eso de por sí es interesante pues significa una posición mucho más de avanzada que la de algunos gobernantes latinoamericanos que simplemente no hacen nada, pues como dicen muchos Chicago Boys, la mejor política económica es la que no existe. O sea, mejor es no hacer nada.

¿Cuáles son los planteamientos de política económica de Obama? Son los siguientes:

"Porque allí donde miremos, hay trabajo que hacer. El estado de la economía requiere una acción audaz y rápida y actuaremos no sólo para crear nuevos empleos sino para levantar nuevos cimientos para el crecimiento. Construiremos carreteras y puentes, las redes eléctricas y las líneas digitales que alimentan nuestro comercio y nos mantienen unidos. Pondremos a la ciencia en el lugar donde se

5 Obama, Barack. Discurso del 21 de enero del 2009 en la Casa Blanca, Washington, Estados Unidos de América.

6 Instituto Peruano de Economía. Ver www.ipe.org.pe. Lima, 29 de enero del 2009.

7 Obama, Barack. Discurso del 21 de enero del 2009 en la Casa Blanca, Washington, Estados Unidos de América. 
merece y aprovecharemos las maravillas de la tecnología para aumentar la calidad de la sanidad y reducir su coste. Utilizaremos el sol, el viento y la tierra para alimentar a nuestros automóviles y hacer funcionar nuestras fábricas. $Y$ transformaremos nuestras escuelas y universidades para hacer frente a las necesidades de una nueva era" ${ }^{8}$.

Podemos señalar las prioridades de la política económica de Obama, donde el Estado hará, contratará o licitará obras para empleo masivo en los siguientes rubros:

\section{Infraestructura física como carreteras y puen-} tes. A veces es difícil imaginar qué nueva carretera se puede hacer en ese gigantesco país ya cruzado una y varias veces por decenas de carreteras en excelente estado de conservación y mantenimiento. Claro que se puede mejorar, haciendo las pistas más modernas y resistentes a los tornados que suelen azotar el país. Lo que sucedió en New Orleans está fresco en la memoria como el desastre ocurrido en el país más desarrollado del mundo. Sin embargo, la construcción de estas obras demanda empleo, ingeniería, cemento, acero, agregados y otros que dinamizarán muchas actividades industriales, empresas y darán empleo productivo a mucha gente. Además su efecto multiplicador hacia adelante será impresionante con menores costos de transporte, mayor comercio y desarrollo del turismo.

2. Redes eléctricas. Los apagones son un problema en los Estados Unidos de América y el Canadá, sobre todo cuando las redes se cargan de nieve que las hace ceder. Imagino la renovación de esas redes con todo lo que significa en la industria del cobre, del acero, de la informática y otras. La transmisión tendría que complementarse con la generación, pero eso demandaría mayor tiempo que solo 4 años de gobierno.

3. Líneas digitales. La comunicación y el comercio se multiplican si los costos disminuyen en la red, y si la competencia se agudiza. Microsoft, tantas veces acusada de prácticas monopolistas, tendrá que vérselas con una competencia auspiciada desde el Estado -que dejará de ser inmovilista- para ser un impulsor consciente del crecimiento y desarrollo económico; justo lo contrario de lo que propone el segundo gobierno de García.

4. La ciencia en el lugar que merece. El desarrollo de las ideas, la ciencia y la tecnología es muy importante por ser elementos importantes de la competitividad de un país. La cantidad de empleos que se puede crear para los sectores poblacionales de alto nivel de calificación o de alto nivel de creatividad son muy grandes; más aún en un país que destina importantes recursos públicos y privados hacia su sistema de ciencia y tecnología, universidades públicas y privadas, así como a instituciones ligadas a la innovación. Así, podemos comparar la situación de nuestro país en el ranking de la competitividad mundial ${ }^{9}$ :

Gráfico N. ${ }^{\circ 2}$

Perú: Principales pilares de competitividad 2008 (En puesto)

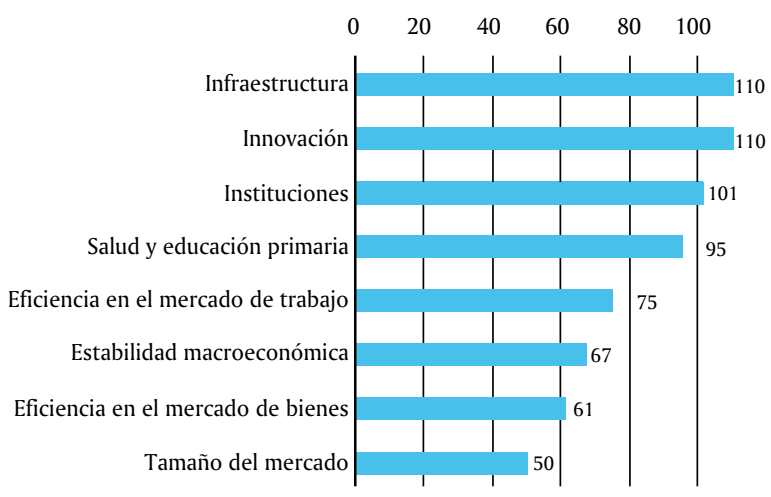

Fuente: World Economic Forum / Elaboración: Instituto Peruano de Economía

*En ranking de 134 economías.

5. El cambio climático es una amenaza mundial. Al Gore en su película "La Verdad Incómoda" -de gran éxito por su calidad y por la información brindada, y que le sirvió para ganar el Premio Nóbel- hace una advertencia muy documentada ${ }^{10}$. Es muy difícil ignorar la situación apremiante y los impactos cada vez más fuertes a futuro.

El calentamiento global inducido por la acción humana es una realidad: la temperatura ha subido $0.6^{\circ} \mathrm{C}$ en el siglo XX (en el Ártico, $5^{\circ} \mathrm{C}$ ); en el hemisferio norte los glaciares de las mon-

8 Op. cit

9 Instituto Peruano de Economía. Ver www.ipe.org.pe. Lima, 04 de febrero del 2009.

10 Gore, Al. (2006). La Verdad Incómoda. Película filmada en los Estados Unidos de América. 
tañas se han reducido en un 25\% en 30 años; migraciones de especies animales y vegetales a latitudes más altas; modificación de las fases de reproducción en especies vegetales y animales, $\mathrm{y}$ aumento de la frecuencia e intensidad de fenómenos extremos (huracanes y tifones).

Las consecuencias del calentamiento global son impactantes: cambio del clima y micro climas (régimen de lluvias, sequías, inundaciones); aumento del nivel del mar; posibilidad de interrupción de la corriente termohalina y de la corriente del golfo. El informe Stern, publicado en el 2006, sitúa los costos del cambio climático entre el $5 \%$ y el $20 \%$ del PBI mundial (costo de mitigación: 1\%)

6. La educación recibe prioridad en su planteamiento: transformar escuelas y universidades. Es allí donde se forman y promueven las capacidades y destrezas, y por allí es certero su enfoque.

También plantea una posición respecto al problema del mercado: ison las fuerzas de la oferta y de la demanda las que deben regir la economía? ¿Son las fuerzas de la oferta y de la demanda las fuerzas irracionales que el hombre debe dominar para conducirlas a favor de la sociedad? Su punto de vista es el regreso al enfoque de Keynes, de manejar la política económica de los Estados Unidos de América, y con gran facilidad podemos concluir que su influencia hará impacto en los gobiernos, empezando por los más débiles, en América Latina. Así:

"La cuestión para nosotros tampoco es si el mercado es una fuerza del bien o del mal. Su poder para generar riqueza y expandir la libertad no tiene rival, pero esta crisis nos ha recordado a todos que sin vigilancia, el mercado puede descontrolarse y que una nación no puede prosperar durante mucho tiempo si favorece sólo a los ricos. El éxito de nuestra economía siempre ha dependido no sólo del tamaño de nuestro Producto Nacional Bruto sino del alcance de nuestra prosperidad, de nuestra habilidad de ofrecer oportunidades a todos los que lo deseen, no por caridad sino porque es la vía más segura hacia el bien común"11.
Es paradójico que utilice el lenguaje de "sólo para los ricos", frase muy parecida a la que usó Lourdes Flores, dos veces candidata a la presidencia de la república del Perú, refiriéndose al actual mandatario Alan García. Ella señaló:

"La lideresa del Partido Popular Cristiano (PPC), Lourdes Flores Nano, evaluó el mensaje presidencial del pasado 28 de julio y concluyó su análisis afirmando que 'Alan García Pérez es el presidente de los ricos, sin la menor duda, porque su gobierno es tremendamente conservador' y mantiene el statu quo sin las reformas que pide la ciudadanía"12.

Quizá algunos puedan pensar que Obama copió a Lourdes Flores la frase entera o parte de ella, pero creo que no es así. Lo que pasa es que el modelo neoliberal en su planteamiento señala que los agentes de mayor ahorro (utilidades) son aquellos que pueden invertir más (Ahorro = Inversión), razón por la cual es necesario dejar que optimicen todo lo posible sus utilidades. Por ejemplo, el modelo de Romer considera que en lugar de suponer que el crecimiento ocurre debido a mejoras automáticas y no modeladas (exógenas) en la tecnología, la teoría se concentra en la comprensión de las fuerzas económicas subyacentes en el progreso tecnológico. Una contribución importante es el reconocimiento de que el progreso tecnológico se produce cuando las empresas maximizadoras de ganancias o los inventores buscan nuevas y mejores "ratoneras". En consecuencia, la innovación depende de la maximización de las ganancias de las empresas; el Estado no tiene por que intervenir.

\section{EL IMPACTO DE LA POLÍTICA ECONÓMICA DE LOS ESTADOS UNIDOS DE AMÉRICA EN EL PERÚ}

No bien ganó las elecciones el presidente Obama en los Estados Unidos de América el mandatario peruano planteó su programa anti crisis. Le era necesario para ser bien visto por Obama, pues de por medio estaba el Tratado de Libre Comercio (TLC), única gestión a nivel internacional que puede presentar como exitosa. No la inició él, pero su culminación y puesta en ejecución puede ser bien vista por los sectores de consumo medio y alto de la población del país.

11 Obama, Barack. Discurso del 21 de enero del 2009 en la Casa Blanca, Washington, Estados Unidos de América.

12 Diario Perú 21. "Lourdes Flores: Alan García es el presidente de los ricos”. Ver: www.peru21.com.pe Lima, 31 de julio del 2008. 
García giró rápidamente de un enfoque neoclásico (de libre mercado) a un enfoque keynesiano (de gasto público y acción estatal). Dos elementos marcan el giro del mandatario: el primero es político, pues quiere llevarse bien con el gobernante norteamericano. El segundo es económico, y es que a pesar que muchos de los analistas de la escena oficial (los que aparecen en los medios de comunicación masiva, auspiciados por empresas o partidos) señalaron que la economía peruana estaba blindada, la situación no es tal, y el engaño público fue poco a poco desmentido por la realidad empresarial. La coyuntura internacional hizo, por fin, que el gobernante peruano reconociera lo contrario que los economistas y analistas afines al modelo neoliberal que auspicia el gobierno peruano. Así, reconoció la grave crisis financiera que vive el mundo y que es necesario hacerle frente para evitar consecuencias sociales $\mathrm{y}$, por qué no, políticas (imagino que conoce lo de Islandia). En el primer paquete de medidas anunció S/. 10,000 millones para promover el empleo y continuar con el crecimiento económico que permitirá a la economía y sociedad peruana afrontar las tendencias a la recesión mundial.

Las perspectivas no son alentadoras. Así, tenemos que el Instituto Peruano de Economía trata de presentar un cuadro moderado de perspectivas $^{13}$ :

\section{Gráfico No3}

Balanza Comercial, 1997-2009

(en miles de millones de US\$)

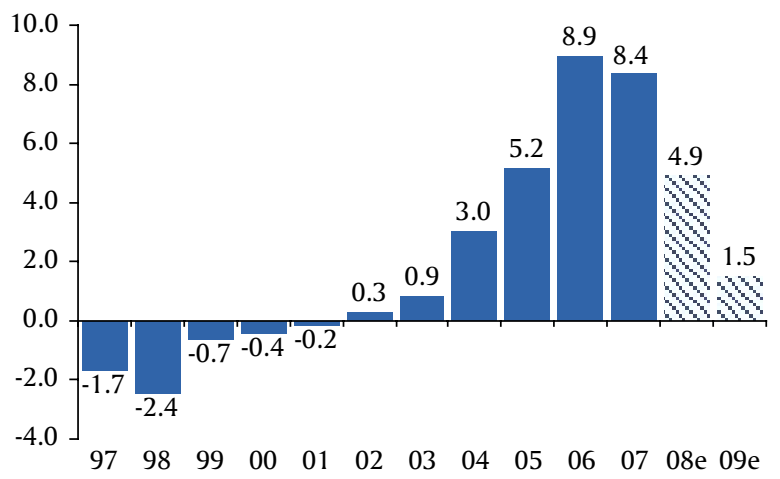

Las exportaciones disminuyen en cantidad y precio, y las importaciones se incrementan por el impulso de consumo a crédito que la población nacional ha asumido creyendo que el Perú está "blindado". La tendencia es a una disminución notable del superávit en la Balanza Comercial y cada mes que pasa, con la nueva estadística se aprecia un ajuste de las perspectivas hacia abajo: menor superávit, déficit en cuenta corriente, menor empleo, menor incremento del PBI, lo que significa también mayor pobreza y las consecuencias de ello.

Por otro lado, el presidente García señaló la previsión de una línea de crédito de US\$ 3,000 millones para cubrir las necesidades de gastos e inversiones que pudiera requerir el país. A ello se sumaría una línea de crédito internacional de US\$ 7,000 millones, en caso que el monto previsto sea insuficiente. Las cifras de endeudamiento son enormes para Perú, y significan casi otro presupuesto de la República.

Una de las cuentas nacionales de mayor preocupación es la Balanza en Cuenta Corriente, pues tiene que ver con los ingresos y egresos de divisas que impactan severamente en el tipo de cambio. Las perspectivas moderadas son las siguientes ${ }^{14}$ :

\section{Gráfico No 4}

Balanza en Cuenta Corriente, 1997-2009 (como \% del PBI)

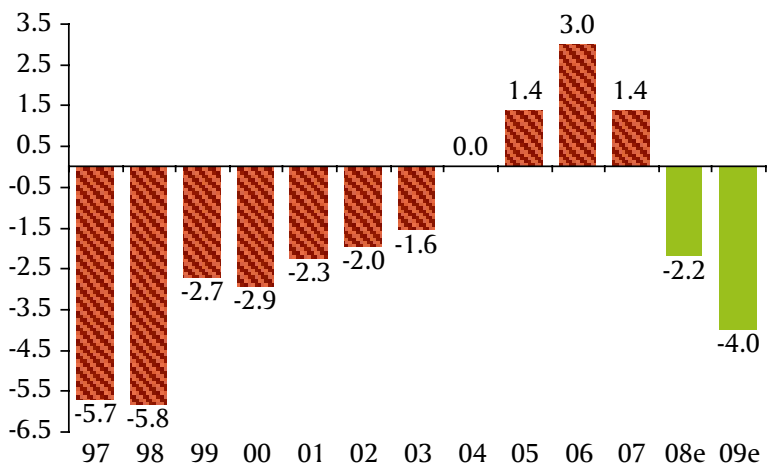

Las cifras aún no recogen el impacto global de la crisis de los Estados Unidos de Norteamérica o de Europa en su conjunto. García considera que el Perú está en mejor situación que los “... países más poderosos que el nuestro".

El sector construcción de la economía peruana es el que más ha crecido en los últimos años, impulsando hacia arriba al Producto Bruto Interno por esta razón el plan ofrece el desembolso de dinero para los créditos hipotecarios. Mencionó que el Estado tiene previsto entregar US\$ 900 millones para que COFIDE los destine a entidades

13 Instituto Peruano de Economía. “Perspectivas de la Economía Peruana”. Lima, 23 de octubre del 2008.

14 Op. cit. 
financieras para viviendas, y así lograr que el sector construcción no se afecte por la crisis.

También mencionó acelerar las carreteras ya presupuestadas. Las carreteras serán prioritarias y planteó acortar los plazos para la construcción de las principales vías de comunicación. Un caso mencionado es el de las carreteras AyacuchoAbancay; Chongoyape-Cochabamba y Tingo María-Pucallpa.

Alan García hizo recordar su primer gobierno cuando retó al sector privado a invertir más con los recursos obtenidos durante años anteriores, pero las perspectivas de los empresarios son diferentes. Muchos de ellos son pesimistas, tal como vemos en el siguiente gráfico ${ }^{15}$ :

Gráfico No5

Encuesta del Banco Central a empresarios ¿Cómo considera usted que se comportará la economía en los próximos tres meses? (en porcentaje)

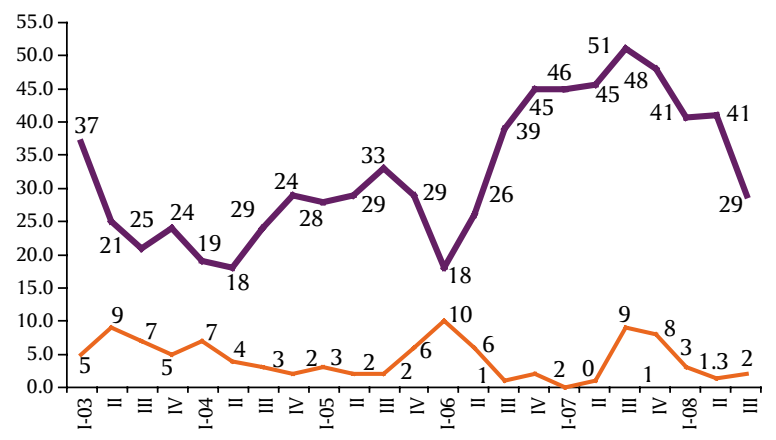

La confianza en el gobierno de García cae con el blindaje que decía tenía la economía peruana. Los empresarios que han optimizado sus ganancias o beneficios no ven con buenos ojos los años que se vienen. Así, las inversiones disminuirán, y nuevamente tendremos a un García burlado por los empresarios, como ocurrió en su gobierno anterior. El reto de García caerá en oídos sordos, pues los empresarios no están dispuestos a arriesgar sus fondos, como García sí lo hace con los fondos estatales.

El riesgo se encuentra en que las medidas no son un conjunto orgánico y lógico; son gastos en obras desconectadas unas de otras, y cuyo impacto es en todo caso regional o local.

Nuevamente las fuerzas vivas del país reconocen la carencia de planificación nacional del desarrollo. Otro gobernante más que confió en el mercado más que en su gente de gobierno: ¿otra oportunidad perdida?

\section{CONCLUSIONES}

1. El entorno de la crisis financiera internacional se complica con problemas de tipo económico y de tipo político.

2. Barack Obama plantea un gran programa de obras públicas para dar empleo a los residentes de los Estados Unidos. Recurre a un antiguo planteamiento keynesiano abandonado por Bush y por algunos gobernantes ultra liberales de América Latina.

3. Se hacen evidentes las grandes flaquezas del blindaje de la economía peruana: empresas que cierran, desempleo creciente y tendencia al alza del tipo de cambio; un entorno desfavorable para la gestión empresarial durante el 2009.

4. La ausencia de planificación del gobierno liberal de García traerá las consecuencias. Al decir de Obama, los "codiciosos" no invertirán, y la población peruana pagará los costos del error al elegir su gobierno.

\section{RECOMENDACIONES}

1. Es urgente la conformación de un gobierno nacional con integrantes que se alejen del manejo neoliberal. La recomposición tiene que empezar desde el Ministerio de Economía y Finanzas.

2. Las obras públicas planteadas por García no son lo mejor. Construir viviendas es crear empleo hasta que terminen de construir las viviendas, y luego la vivienda no genera mayor producto. Es diferente si se hacen obras planeadas con anticipación, como la segunda vía de la Carretera Central, o la modernización del Puerto de Pisco, o el Oleoducto Sur Peruano, que sí tienen efecto multiplicador hacia adelante, además de las consecuencias positivas que trae su construcción.

3. Subsidiar empresas a través de la devolución de impuestos sólo beneficia a las que ya están exportando, además de no hacerlas competitivas. El manejo del tipo de cambio es errado y la devaluación la imponen los especuladores contra el propósito del Banco Central de Reserva. Corregir el error le costará caro a la economía y a la popularidad del presidente García.

15 Op. cit. 
4. Las ganancias extraordinarias no regresarán al país, y los pocos ahorros que el Estado logró al incrementar sus reservas internacionales netas se están perdiendo. La reforma tributaria es necesaria para así cautelar el derecho del Estado sobre sus recursos y sobre la gestión empresarial y sector laboral del país.

\section{BIBLIOGRAFÍA}

Fernández de Lis, Santiago. (2009). Lacrisisfinanciera, su impacto y la respuesta de las autoridades. Madrid, Ediciones Empresa Global.

García Alvarez-Coque, José María; Ochando Claramunt, Carlos; Picher i Campos, Josep Vicent; García Reche, Andrés; Jordán Galduf, Josep María.( 2003) Política Económica. Madrid, Editorial Tirant Lo Blanch.
Martínez Pizarro, Jorge. (2008). América Latina y El Caribe: migración internacional, derechos humanos y desarrollo. Santiago de Chile, CEPAL-Naciones Unidas-CELADE.

Natanson, José. (2007). Buenos muchachos, vida y obra de los economistas del Establishment. Buenos Aires, Ediciones del Zorzal.

Restoy, Fernando. (2009). La crisis financiera su impacto y la respuesta de las autoridades". Madrid, Ediciones Empresa Global.

Rodríguez Herrera, Adolfo y Alvarado Ugarte, Hernán. (2008). Claves de la innovación social en América Latina y El Caribe. Santiago de Chile, CEPAL-Naciones Unidas-CELADE.

Von Mises, Ludwig. (2007). Política económica (seis lecciones sobre el capitalismo). Madrid, Unión Editorial. 